\title{
ANAP

\section{ENTRE A QUALIDADE DE VIDA E O CAPITAL: A APA DO MARAPENDI E O GRAND HYATT HOTEL.}

\author{
Luciana Crivelare Gomes Carvalho ${ }^{1}$
}

Ana Carolina Católico ${ }^{2}$

\begin{abstract}
RESUMO
Este artigo alerta sobre a construção do resort Grand Hyatt Hotel na antiga Área de Proteção Ambiental do Marapendi, no bairro da Barra da Tijuca, cidade do Rio de Janeiro. Apesar da Rede Hyatt contar com forte propaganda e marketing verde, afirmando ser possuidora de selos de sustentabilidade em seus empreendimentos ao redor do mundo, a opção feita no Rio de Janeiro não pareceu sustentável. No ano de 2013, quando as obras eram iniciadas, moradores e usuários de tal espaço, organizados, fizeram manifestações no local da obra, alcançando a atenção de autoridades que, por sua vez, conseguiram que embargassem parte da área de construção do hotel. A repercussão desta escolha para o grupo hoteleiro tornou-se custosa, a ponto de até hoje (2015) manter esclarecimentos no próprio website do hotel, com declarações elucidativas sobre a escolha do lugar, sobre as promessas de medidas compensatórias e os cuidados que o hotel pretende tomar para ser 'ecologicamente correto'. A questão que fica é: após o desmatamento da APA e do desequilíbrio promovido no local, existem medidas capazes de sanar a insustentabilidade deste empreendimento?
\end{abstract}

PALAVRAS-CHAVE: Grand Hyatt Hotel. Área de Proteção Ambiental. Insustentabilidade.

\section{BETWEEN THE QUALITY OF LIFE ANDCAPITAL: THE APA OF MARAPENDI AND GRAND HYATT HOTEL.}

\begin{abstract}
This article discusses the construction of the Grand Hyatt Hotel resort in the Environmental Protection Area Marapendi in the neighborhood of Barra da Tijuca, Rio de Janeiro. Despite the Hyatt Network works on strong and green marketing, asserting to be possessed of sustainability seals in their endeavors around the world, the choice made in Rio de Janeiro did not seem sustainable. In 2013, when the works were started, residents and users of the area, organized, manifestations on site, bringing the attention of authorities who, in turn, obtained the suspension of part of the hotel construction. The repercussions of this choice for the hotel group has become costly until nowadays. In 2015, they still maintain clarification in the hotel's own

\footnotetext{
${ }^{1}$ Geógrafa (UFRRJ), mestranda em Engenharia Urbana (UFRJ).

luciana_crivelare@hotmail.com.

${ }^{2}$ Engenheira de Petróleo e Gás (UFRJ), mestranda em Engenharia Urbana (UFRJ). anacatolico@gmail.com.
} 


\section{ANAP

website, with enlightening statements on the choice of place on the promises of compensation measures and the care that the hotel intends to take to be 'environmentally friendly'. The question that remains is: after deforestation the APA and promoted imbalance on site, there are measures to remedy the unsustainability of this development?

KEY WORDS: Grand Hyatt Hotel. Environmental Protection Area. Unsustainability.

\section{ENTRE LA CALIDAD DE VIDA Y CAPITAL: EL APA DE MARAPENDI Y GRAND HYATT HOTEL.}

\section{Resumen}

Este artículo advierte sobre la construcción de Grand Hyatt Hotel en la antigua zona de protección del medio ambiente en Marapendi, en el barrio de Barra da Tijuca, Río de Janeiro. Aunque la red Hyatt dependen fuerte publicidad y marketing verde, alegando que con sellos de sostenibilidad en sus proyectos alrededor del mondo, la opción hecha en Río de Janeiro no parecía sostenible. En el año 2013, cuando se iniciaron las obras, los residentes y usuarios de ese espacio, organizado, hicieron demostraciones en el sitio de construcción, llegando a la atención de las autoridades que, a su vez, se embargassem parte del área de la construcción del hotel. El efecto de esta opción para el grupo hotelero se convirtió en costoso hasta el punto de hoy (2015) clarificación en la web del propio hotel, con ningunas declaraciones sobre la elección del lugar, acerca de la promesa de medidas compensatorias y el cuidado el hotel tiene intención de adoptar para ser 'medio ambiente'. ¿La pregunta que queda es: después de la deforestación de APA y promovido en el lugar, hay desequilibrio son medidas para remediar la insostenibilidad de este emprendimiento?

PALABRAS-CLAVES: Grand Hyatt Hotel. Area de Proteccion Ambiental Medio. Insostenibilidad.

\section{INTRODUÇÃO}

Defende-se que entre a preocupação ambiental e a possibilidade de lucro, o segundo quase sempre permanecerá à frente do primeiro. Ainda que uma parte da área delimitada (área de lazer) para a construção tenha sido embargada, a implantação deste empreendimento segue a passos largos. Será que a partir do funcionamento do hotel, e dos impactos negativos que claramente irão surgir, o caso receberá sua devida atenção? Abaixo foi exposta a imagem com o protótipo do hotel, publicado no site do Grand Hyatt Hotel do Rio de Janeiro: 


\section{ANAP Brasil \\ ISSN 1904-3240 \\ v. 8, n. 13}

\section{REVISTA CIENTIFICA}

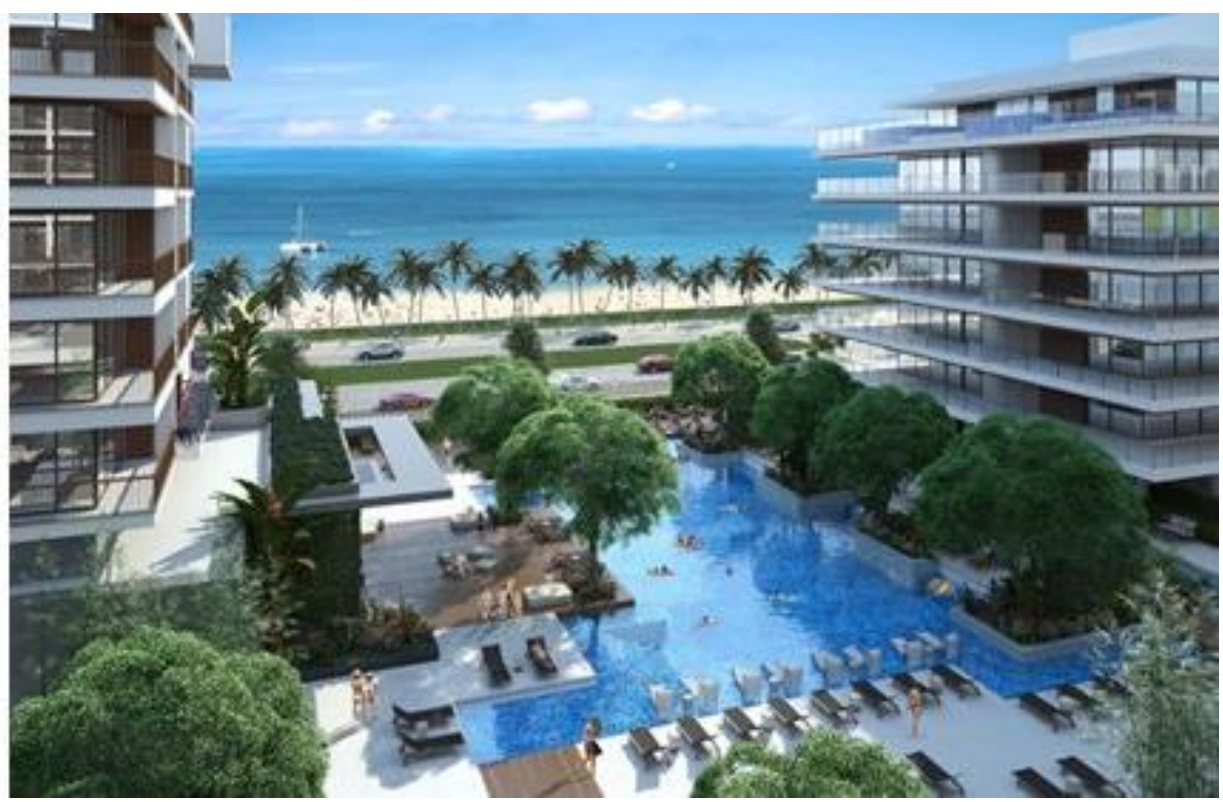

Figura 1: Grand Hyatt Hotel no Rio de Janeiro, APA do Marapendi. ${ }^{3}$

O Rio de Janeiro é uma cidade mundialmente conhecida por suas belezas naturais, por sua riqueza cultural e pelos frequentes eventos de entretenimento. Ainda que a cidade também seja reconhecida pela violência e infraestrutura urbana precária (principalmente na área de transportes, demasiadamente utilizada pelos turistas), segue sendo um dos destinos preferidos para viagens de lazer. A consultoria Euromonitor International publicou, em 2015, uma lista com as 100 cidades mais visitadas do mundo, a única cidade brasileira que entrou nesta lista foi o Rio de Janeiro, como a tabela mostra abaixo:

${ }^{3}$ Site www.grandhyatthoteriodejaneiro.com.br acessado em 12 de agosto de 2015. 


\section{ANAP Brasil \\ ISSN 1904-3240 \\ v. 8, n. 13}

\section{5}

\begin{tabular}{ll}
\hline \multicolumn{2}{c}{ Lista das cidades mais visitadas do mundo } \\
\hline & \\
$1^{\circ}$ - Hong Kong (Hong Kong) & $91^{\circ}$ - Melbourne (Austrália) \\
$2^{\circ}$ - Cingapura (Cingapura) & $92^{\circ}$ - Rio de Janeiro (Brasil) \\
$3^{\circ}$ - Bangcoc (Tailândia) & $93^{\circ}$ - Riad (Arábia Saudita) \\
$4^{\circ}$ - Londres (Reino Unido) & $94^{\circ}$ - Amã (Jordânia) \\
$5^{\circ}$ - Paris (França) & $95^{\circ}$ - Sousse (Tunísia) \\
$6^{\circ}$ - Macau (Macau) & $96^{\circ}$ - Kiev (Ucrânia) \\
$7^{\circ}$ - Nova York (EUA) & $97^{\circ}$-Sharjah (Emirados) \\
$8^{\circ}$ - Shenzhen (China) & $98^{\circ}$ - Jeju (Coreia do Sul) \\
$9^{\circ}$ - Kuala Lumpur (Malásia) & $99^{\circ}$ - Krabi (Tailândia) \\
$10^{\circ}$ - Antalya (Turquia) & $100^{\circ}$ - Artvin (Turquia) \\
\hline
\end{tabular}

Figura 1: As 100 cidades mais visitadas do mundo. Fonte: Euromonitor International (2015).

Pelos motivos expostos acima e por sediar megaeventos desde o ano de 2007, com o Pan-americano, Rio+20 (2012), Jornada Mundial da Juventude (2013), seguida da Copa de Mundo (2014) e das Olimpíadas (2016), investidores e empreendedores da indústria de turismo e entretenimentos tem injetado capital na cidade, principalmente, na construção de hotéis. $O$ presidente da Empresa Brasileira de Turismo (EMBRATUR), Vinicius Lummertz, declarou que o Brasil, em especial a Barra da Tijuca, no Rio de Janeiro, mostrou ter condições favoráveis para organizar e receber grandes eventos, como vem acontecendo desde 2007. Já o diretor de Desenvolvimento de Novos Negócios da Accor (grande empresa hoteleira) na América Latina, Abel Castro, declarou, no ano de 2013, que a demanda por hotéis no Rio de Janeiro continuaria em forte progressão, sustentada pelo crescimento das indústrias, principalmente petroquímica e automotiva; da economia do conhecimento, com universidades e centros de pesquisa; e dos grandes eventos internacionais.

O Fórum de Operadores Hoteleiros do Brasil (FOHB) informou que a taxa de ocupação média nos hotéis do Brasil cresceu 2,7\%, em 2011, e fechou 


\section{ANAP $B_{\text {rasil }}$ \\ ISSN 1904-3240 \\ v. 8, n. 13}

o ano em 69,14\%. Desde 2005, este foi o melhor resultado alcançado. Associação Brasileira da Indústria de Hotéis do Rio de Janeiro (ABIH-RJ) afirma que até 2016 a Barra da Tijuca terá 11 mil quartos de hotéis disponíveis; investimento este incentivado pelos Jogos Olímpicos, uma vez que a região foi escolhida como palco de distintas disputas, atraindo mais de $60 \%$ de novos investimentos hoteleiros para o bairro.

Dentre os hotéis que foram atraídos para a cidade do Rio de Janeiro, o Grupo Hyatt foi um dos principais. A Rede Hyatt tem uma proposta diferenciada em relação a outros hotéis. Além de estar presente nos cinco (05) continentes, possuindo mais de duzentos (200) empreendimentos ao redor do mundo, é conhecido por construir hotéis de grande porte e extremamente luxuosos. O público alvo não se resume a turistas, senão turistas de alta classe e grandes empresários, havendo espaços próprios para conferências e reuniões de negócios no hotel.

Estão sendo construídos edifícios residenciais com amplas suítes, com áreas privativas a partir de $120 \mathrm{~m}^{2}$, colocados à venda desde o segundo semestre de 2012. Ou seja, fica patente o público que o hotel pretende ter como cliente. A empresa imobiliária responsável pelas vendas do anexo do Grand Hyatt Hotel do Rio de Janeiro, a Patrimóvel, um gigante do setor imobiliário

Todavia, existe um percalço - ou pelo menos deveria ser um - sobre a área que foi escolhida para construir o Grand Hyatt Hotel: era uma Área de Proteção Ambiental (APA). Sob antiga tutela da Secretaria Municipal do Meio Ambiente, a área do Parque do Marapendi possuía aproximadamente 248 hectares. Localizado na faixa litorânea da Barra da Tijuca, entre a Avenida Lúcio Costa e a Avenida das Américas, às margens da Lagoa de Marapendi. Das áreas que permaneciam sob proteção do parque, 245 hectares encontramse na Barra da Tijuca e 3 hectares no Recreio dos Bandeirantes.

Quanto a cobertura vegetal da APA de Marapendi, segundo o Manual Técnico de Vegetação do Instituto Brasileiro de Geografia e Estatística (IBGE) 


\section{ANAP $B_{r a s i l}$ \\ ISSN 1904-3240 \\ v. 8, n. 13}

classifica como Formações Pioneiras de Terras Baixas (manguezal e restinga). Ressalta-se isto pois, como se sabe, tais ecossistemas correm risco de extinção devido a sua fragilidade e a realidade ambiental presentes nos grandes centros. Tanto a fauna quanto a flora, com uma biodiversidade excêntrica, possui desde diferentes grupos de moluscos, a crustáceos, saguis, aves entre outros animais. $\mathrm{Na}$ área arenosa, a vegetação é composta por espécies halófitas, psamófitas e subarbustivas; desenvolvendo o manguevermelho, mangue-siriúba e o mangue-branco.

Um dos possíveis motivos para a liberação da construção do Grand Hyatt Hotel é a importância desconhecida da Área de Proteção Ambiental que, por muito tempo, não teve seu valor reconhecido por profissionais do meio ambiente e acadêmicos; uma vez que esta classificação permite certa ocupação humana e uso sustentável do local. Vale ressaltar que a antiga Área de Proteção Ambiental, atual terreno do Grand Hyatt Hotel, está delimitada por três áreas: Zona de Ocupação Controlada (ZOC), Zona de Conservação da Vida Silvestre (ZCVS) e Zona de Proteção da Vida Silvestre (ZPVS).

Com 0 intuito de modificar esta realidade, o Ministério do Meio Ambiente (MMA) organizou, no ano de 2013, o I Seminário das Áreas de Proteção Ambiental do Brasil, com o objetivo de chamar a atenção para a devida causa, de contribuir para o aprimoramento da gestão da categoria e coletar subsídios para a definição de recomendações para a criação e implementação da categoria.

\section{Objetivo}

O objetivo deste ensaio é refletir sobre a validade dos argumentos de sustentabilidade utilizados no marketing do grande empreendimento hoteleiro que vem sendo desenvolvido desde o ano de 2013 na Praia da Reserva, Barra da Tijuca. 


\section{ANAP Brasil \\ ISSN 1904-3240 \\ v. 8, n. 13}

\section{REVISTA C I EN TIF I CA A}

\section{METODOLOGIA}

As etapas desta pesquisa foram:

[1] Revisão Bibliográfica;

[2] Trabalho de Campo: acompanhamento das manifestações;

[3] Entrevista com moradores e usuários do espaço;

[4] Conclusões.

\section{CONCLUSÕES}

A escolha da APA para a construção do hotel e a decorrente supressão foi repudiada pelos moradores e frequentadores da área, que organizaram diferentes manifestações no local, a fim de chamar atenção das autoridades, como pode ser visto nas imagens abaixo:

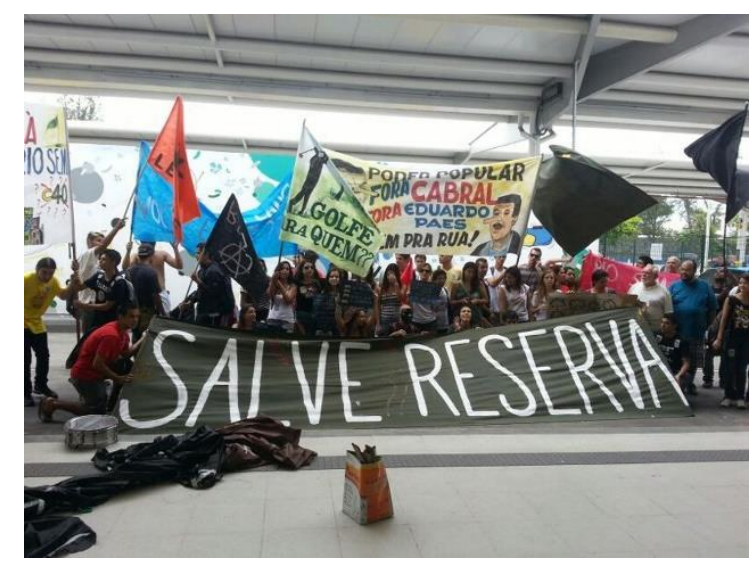

Figura 2: Protesto contra desmatamento da APA do Marapendi. Fonte: G1.

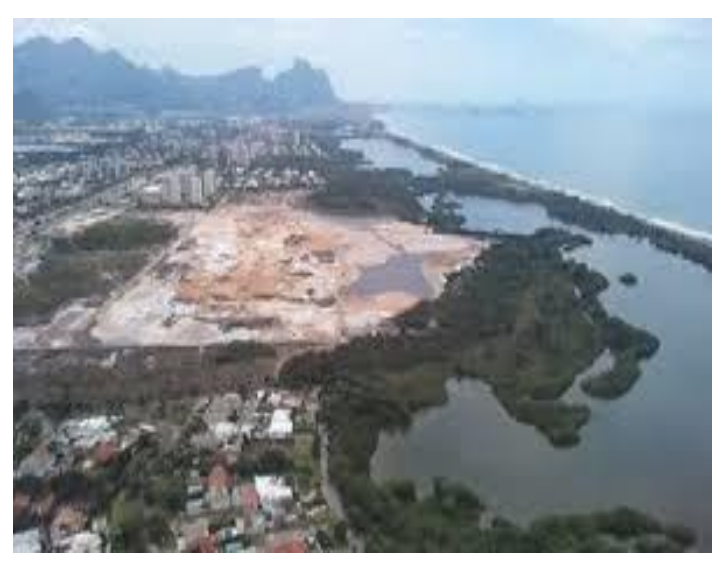

Figura 3: Área para construção do Grand Hyatt Hotel. Fonte: Urbe Carioca.

Incrivelmente, o Rio de Janeiro ainda possui praias aptas para serem usadas por banhistas. A Praia da Reserva foi reconhecida pelo Instituto Estadual do Ambiente (INEA) como a praia possuidora de melhores condições 


\section{ANAP $B_{r a s i l}$ \\ ISSN 1904-3240 \\ v. 8, n. 13}

para banhista em território carioca. Não só a Praia da Reserva, mas as praias do litoral da Zona Oeste carioca, publicou Marilene Ramos, presidente do INEA, em dezembro de 2012.

No mesmo ano (2012), o Grupo Hyatt anunciou o início das obras em frente à praia da reserva, entre Barra da Tijuca e Recreio, inclusive com incentivos fiscais por parte do governo, para que estimulasse o grupo hoteleiro na abertura de novos hotéis no estado, e atender à demanda gerada pelos demais megaeventos.

Até que ponto a implantação do hotel não limitará o uso dos cidadãos que já estavam habituadas a frequentar a praia? Quanto à qualidade da água para banho, será que permanecerá sendo mesma? São grandes as chances dos moradores e frequentadores do local sofrerem com os impactos consequentes da implantação do hotel?

O conceito de sustentabilidade não se resume apenas à questão ambiental, mas, sim, a social, econômica e cultural. Sustentabilidade engloba 0 bem comum. Não se pode pensar no lucro de uma empresa ou de um pequeno grupo, quando um grupo demasiadamente maior de pessoas sairá afetado. Pode-se considerar a escolha da antiga APA do Marapendi um local equivocado para ser implantado este empreendimento deste porte pelas seguintes questões:

[1] Trânsito: a Zona Oeste carioca é a região que mais cresce na cidade (ADEMI, 2013), no entanto, sem o devido acompanhamento de investimento público. Segundo o Relatório Técnico da Prefeitura do Rio de Janeiro, relativo a investimentos em infraestrutura por Área de Planejamento, a AP4, área que a Barra da Tijuca se encontra inserida, é a segundo menor em porcentagem recebimento de investimentos voltados para a infraestrutura urbana (previstos para 2013 a 2016); tornando, principalmente, a situação de mobilidade pública ainda mais caótica. A Barra da Tijuca e o Recreio dos Bandeirantes são os bairros 


\section{ANAP $B_{\text {rasil }}$ \\ ISSN 1904-3240 \\ v. 8, n. 13}

que podem ser ressaltados com grandes problemas relativos a engarrafamentos e dificuldade de transporte público. Fica aqui a questão: Será que com a criação do Grand Hyatt Hotel o trânsito do Recreio dos Bandeirantes, da Barra da Tijuca e de outros locais próximos não se tornarão piores?

[2] Supressão vegetal: em um momento que se discute a crise ambiental planetária, seria viável optar pela supressão de uma área que era considerada APA? Há muito que uma metrópole do porte do Rio de Janeiro não pode mais permitir o esgotamento de suas reservas naturais. A natureza é um sistema complexo e interdependente. Portanto, a retirada de qualquer espécie abala o todo.

[3] Emissário de Lixo: o hotel está sendo construído sobre um emissário de esgoto que tinha previsão para início de funcionamento em 2014, com projeção de despejar 900 litros por segundo ou 77 milhões de litros por dia de esgoto bruto, no mar da Barra, sem considerar a demanda do hotel. Após seu funcionamento, existe possibilidade de sobrecarregar 0 sistema e contaminar a área.

[4] Microclima: Ainda que seja uma projeção, a supressão da vegetação local unida a construção de prédios de grande porte, traz possibilidade de impacto no microclima.

[5] Apropriação do espaço público: a apropriação do espaço para utilização dos hospedes. Muitos hotéis na zona sul e na zona oeste que se encontram em frente à praia, tomam a área com guarda-sóis e cadeiras do próprio hotel, não sendo permitindo o uso de outra pessoa que não seja hóspede. A privatização do espaço público é a coroação de um empreendimento com largo impacto ambiental e social. 


\section{ANAP $B_{\text {rasil }}$ \\ ISSN 1904-3240 \\ v. 8, n. 13}

[6] Licença Ambiental: situações como essa faz refletir e duvidar sobre a seriedade dos órgãos públicos brasileiros voltados para a proteção e gestão dos espaços verdes. Como uma construção em cima de uma APA teve licença concedida tão facilmente e de forma impenetrável? Ainda que se pesquise sobre 0 assunto, o processo de licenciamento não é claro.

Devido a repercussão negativa dos impactos causados pelo Grupo Hyatt, foram publicados no website ${ }^{4}$ do hotel do Rio de Janeiro esclarecimentos sobre a escolha de utilizar-se de uma APA, sobre as medidas sustentáveis empregadas por eles, contendo desde hortas urbanas, investimento em reflorestamento, comprometendo-se com a plantação de 828 mudas de árvores e com a regeneração e preservação da restinga, e, em parceria com a Secretaria Municipal de Meio Ambiente (SMAC) e o Instituto Estadual de Licenciamento Ambiental (INEA), realizar levantamento arbóreo e vegetativo para a elaboração de projeto paisagístico.

O Grand Hyatt Hotel propala um discurso de hotel vencedor nos quesitos relacionados a empreendimento sustentáveis. Inclusive, o único hotel da rede existente no Brasil, antes da construção do hotel no Rio de Janeiro, sediado em São Paulo, foi vencedor no quesito desenvolvimento sustentável e preservação do meio ambiente ${ }^{5}$. A questão que permanece é: como um grupo que concordou em construir empreendimento de grande porte, excludente, em uma Área de Proteção Ambiental pode ser sustentável? A obra está prevista para ser concluída ainda este ano. Depreende-se que o Grupo Hyatt será com o bônus, e a população, com o ônus desta escolha.

\footnotetext{
${ }^{4}$ Possível de acessar pelo www.grandhyatthotelriodejaneiro.com.br ${ }^{5}$ http://www.estilohyatt.com.br/tag/sustentabilidade/
} 


\section{ANAP

\section{REFERÊNCIAS BIBLIOGRÁFICAS}

BEZERRA, Eron. "Desenvolvimento versus preservação ambiental?" Revista Princípios: Teoria Política e Informação. São Paulo, CDM - Centro de Documentação e Memória/ Fundação Mauricio Grabois, Edição 83, Fev./Mar., 2006, pp. 39-47. Disponível em: http://grabois.org.br/portal/cdm/revista.int.php?id_sessao $=50 \&$ idpublicacao $=192 \&$ id_indice $=157$ 3. Acesso em: 10 de maio de 2015.

BRUNDTLAND, Gro Harlem. COMISSÃO MUNDIAL SOBRE MEIO AMBIENTE E DESENVOLVIMENTO - 1988. Nosso Futuro Comum (Relatório Brundtland). Rio de Janeiro: Fundação Getúlio Vargas, 1988.

CAMARGO, Luis Henrique Ramos. A Geoestratégia da Natureza: A Geografia da Complexidade e a Resistência à Possível Mudança do Padrão Ambiental Planetário. Rio de Janeiro: Editora: Bertrand Brasil, 2012.

CAPERUTO, Ada. "O futuro do planeta passa pela balança da Justiça". Fórum: Revista dos Magistrados do Estado do Rio de Janeiro [Dossiê: Sustentabilidade - Um caminho que passa pelo Direito Ambiental], Ano 10, Número 32, Julho - Agosto -Setembro de 2012, pp. 2025. Disponível em: http://www.planetaverde.org.ar/downloads/forum.pdf. Acesso em: 20 de maio de 2015.

CONSTITUIÇÃO BRASILEIRA. Constituição da República Federativa do Brasil. Brasília: Ministério da Educação, 1988.

DIEGUES, Antonio Carlos. O Mito Moderno da Natureza Intocada. São Paulo: HUCITEC, 1996.

FINK, Daniel Roberto. Roteiro para o Licenciamento Ambiental e outras Considerações, Rio de Janeiro: Forense Universitária, 2004.

FURTADO, Celso. Introdução ao Desenvolvimento: Enforque Histórico-Estrutural. 3. ${ }^{a}$ ed. Rio de Janeiro: Paz e Terra, 2000.

OLIVEIRA NETO, Geraldo Cardoso de; VENDRAMETTO, Oduvaldo; SACOMANO, José Benedito; PERRETTI, Osvaldo D'Angelo; SANTOS, Osmildo Sobral dos. Aliança Sustentável Crescimento Econômico e a Sustentabilidade. IV Congresso Nacional de Excelência em Gestão. Responsabilidade Socioambiental das Organizações Brasileiras. Niteroi, RJ, Brasil, 31 de julho, 01 e 02 de agosto de 2008. Disponível em: http://www.excelenciaemgestao.org/Portals/2/documents/cneg4/anais/T7_0036_0140.pdf. Acesso em: 16 de abril de 2015.

GUERRA, Antônio José Teixeira; CUNHA, Sandra Baptista. Impactos Ambientais Urbanos no Brasil. 9. a ed. Rio de Janeiro: Bertrand Brasil, 2000.

MARIANO-NETO, Berlamino. Textos, Contextos e Pretextos para o Planejamento Ambiental. Paraíba, 2003.

MARTínEZ-ALIER, Joan. O Ecologismo dos Pobres. São Paulo: Editora Contexto, 2007. 


\section{ANAP

MEADOWS, Donella H.; MEADOWS, Dennis L.; RANDERS, Jorgen; BEHRENS III, W. W. Limites do Crescimento: Um relatório para o projeto do Clube de Roma sobre o dilema da humanidade. São Paulo: Editora Perspectiva, 1973.

MURGEL-BRANCO, Samuel. O Meio Ambiente em Debate. 28. ${ }^{a}$ ed. São Paulo: Editora Moderna, 1997.

OLIVEIRA, Leandro Dias de. A Ideologia do Desenvolvimento Sustentável no Ensino da Geografia. 2001. Monografia (Graduação em Geografia) - Departamento de Geografia, Universidade Estadual do Rio de Janeiro (UERJ), Faculdade de Formação de Professores (FFP), São Gonçalo / RJ, 2001.

A geopolítica do desenvolvimento sustentável: um estudo sobre a Conferência do Rio de Janeiro (Rio-92), 2011. 283 p. Tese (Doutorado) - Instituto de Geociências, Universidade Estadual de Campinas (UNICAMP), Campinas - SP.

A geopolítica do desenvolvimento sustentável: Reflexões sobre o encontro entre economia e ecologia. Revista Carta Internacional. ABRI (Associação Brasileira de Relações Internacionais), São Paulo, Volume 7, número 1, 2012, páginas 118-139. Disponível em: http://cartainternacional.abri.org.br/index.php/Carta/article/view/54/36. Acesso em: 13 de junho de 2015.

PORTO-GONÇALVES, Carlos Walter. Os (Des) caminhos do Meio Ambiente. São Paulo: Editora Contexto, 1996.

O Desafio Ambiental. Rio de Janeiro: Editora Record, 2004.

ROSA, Guilherme. "Apocalipse Maia: O mundo não vai acabar em 2012. Mas o que vem depois?" Portal da Revista Veja, 15/12/2012, 17:47h. Disponível em: http://veja.abril.com.br/noticia/ciencia/o-mundo-nao-vai-acabar-em-2012-mas-o-que-vemdepois. Acesso em: 10 de maio de 2015.

SACHS, Ignacy. Caminhos para o desenvolvimento sustentável. Rio de Janeiro: Garamond, 2000.

SILVEIRA DA ROSA, Patrícia. O Licenciamento Ambiental à Luz da Teoria dos Sistemas Autopoiéticos. Rio de Janeiro: Editora Lumen Juris, 2009.

VEIGA, José Eli da. A insustentável utopia do desenvolvimento. In: LAVINAS, Lena, Liana M. F. Carleial, Maria Regina Nabuco (orgs). Reestruturação do espaço urbano e regional no Brasil, S.Paulo: ANPUR-HUCITEC, 1993, pp.149-169. Disponível em: http://www.zeeli.pro.br/wp-content/uploads/2012/06/1993-a_A-insustentavel-utopia-dodesenvolvimento.pdf. Acesso em: 10 de maio de 2015. 